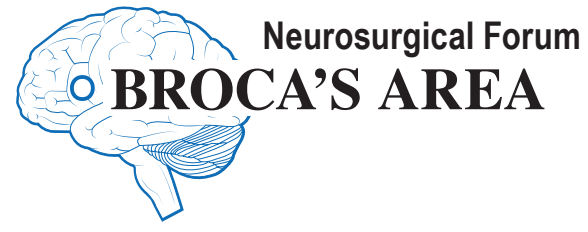

\section{In Memoriam: James Tait Goodrich}

Rick Abbott, MD

Department of Neurological Surgery, Albert Einstein College of Medicine/Montefiore Medical Center, Bronx, New York

I AM deep in thoughts of working with Jim (Fig. 1) as I receive condolences and memories from around the world. I am struck by how many were indebted to him for providing the knowledge and help for their patients with complex problems as well as a friendship they valued greatly. During his career he became a treasure for pediatric neurosurgery and we all now are realizing how difficult it will be to replace him.

After completing his service in the Marines, Jim received his undergraduate degree from the University of California, Irvine, before entering Columbia University's MD PhD program. There he received a Masters and Doctorate of Philosophy from Columbia University's Graduate School of Arts and Sciences and a Doctor of Medicine from Columbia University's School of Medicine in 1980. He completed his residency in neurological surgery at Presbyterian Hospital in New York City and the New York Neurological Institute before accepting a faculty appointment in the Leo Davidoff Department of Neurological Surgery at Albert Einstein College of Medicine in 1986. The department's chairman assigned Jim to care for the children at its hospital, Montefiore. His career in pediatric neurosurgery was launched.

At the time Jim started in pediatric neurosurgery, craniosynostosis and its treatment was a major focus of the discipline. Jim was integral in forming the Craniofacial Center at Montefiore, structuring it to contain not only the surgical expertise required to treat the condition but also specialists in medical genetics. The group's work resulted in the description of several genetic syndromes resulting in craniosynostosis, with the group gaining international recognition of its expertise. He described several variations of craniosynostosis as well as surgical techniques to deal with the condition. Along the way he also contributed

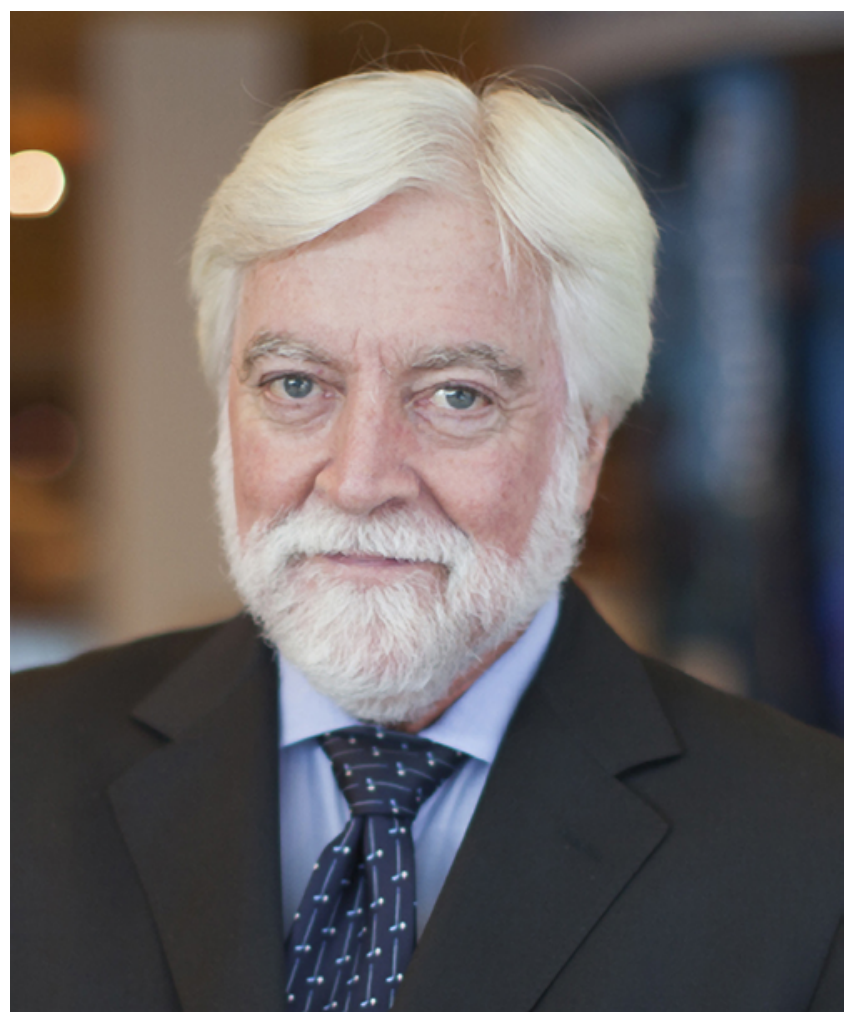

FIG. 1. James Tait Goodrich, MD, PhD. Published with the permission of Montefiore Health System. Figure is available in color online only.

to our knowledge of the history of its treatment. Recently, he entertained fellow neurosurgeons with his critique of endoscopic management of single-suture synostosis, describing its advocates as "strippers." I had the unfortunate assignment in one forum to argue the side of the "strippers" against him. His depth of historical experience with the strip craniectomy technique and his rationale for favoring cranial vault remodeling made my attempt daunting and nearly futile.

Jim did not confine his historical study to craniosynos- 
tosis. He had a deep and voracious hunger for the historical manuscripts of medical science, particularly those dealing with neurosurgery. He was an internationally known bibliophile and antiquarian bookseller. His home contained a medieval library with thousands of books. His care of patients reflected his knowledge of the mistakes of the past, facts he gained from reading these historical manuscripts. Jim was the "go-to guy" in pediatric neurosurgery when a historical perspective was needed, be it for a focused set of manuscripts on treating a condition, or for a pediatric neurosurgery or neurosurgery textbook. He made a powerful argument for the importance of such knowledge.

In 2003 he was approached by a family in the Philippines about their babies with craniopagus. After arranging for their transfer to Montefiore he set about collecting every manuscript written on the condition and its treatment. $\mathrm{He}$ arrived at the clear conclusion that abrupt separation was associated with a high risk for morbidity and mortality. He designed a staged separation of the twins' cranial circulation and was successful in separating the children with minimal inflicted morbidity. As awareness of this feat grew in the professional community, he increasingly was called upon to travel throughout the world helping colleagues treat craniopagus arising in their communities. Jim also contributed numerous publications on other historical treatments for conditions we manage today. These have been a valuable contribution to our knowledge, and we will sorely miss such insight.

Jim was an educator. He readily shared his knowledge, volunteering globally to educate colleagues and assist them with their surgeries. The frequent question in our department was "Is Jim here this week?" He was always available to join a course faculty or speaking roster and the requests were constant given his profound knowledge of neurosurgical history and engaging speaking style. His ability to build a broad and deep base for his theses never failed to give his audience a thorough understanding of his beliefs. This knowledge was also valued by our residents because it gave them an understanding of neurosurgery's history, allowing them to judge the foundations supporting a newly touted treatment and to differentiate a truly valuable insight from a recycled concept that had been historically disproven.

Jim was beloved by his patients and their parents. His demeanor projected a physician with a deep understanding of the child's problem and the commitment to conquering it. His families could read in him a shared goal for realizing the child's potential and the need for protecting it from the disease and its treatment.

Our specialty will have difficulty in filling the void left by Jim's passing. He was beloved and cherished by his colleagues, patients, and their families, who will miss him dearly.

\section{Disclosures}

The author reports no conflict of interest.

\section{Correspondence}

Rick Abbott: rickabbott@me.com.

\section{INCLUDE WHEN CITING}

Published online June 19, 2020; DOI: 10.3171/2020.5.PEDS20351.

CAANS 2020, except where prohibited by US copyright law 